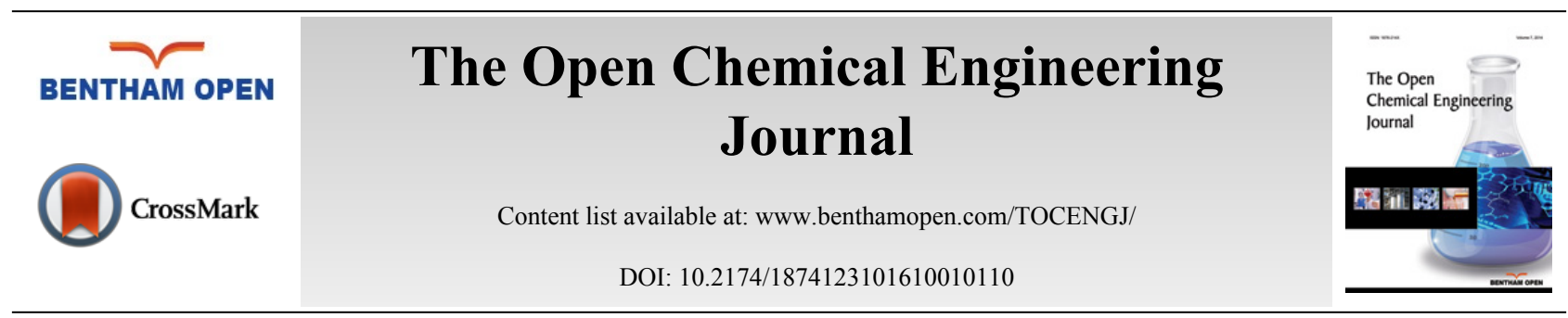

\title{
RETRACTION
}

\section{Retraction Notice: Using Fenton Oxidation Method to Advanced Treatment of Landfill Leachate}

Gao Yanjiao ${ }^{1}$, Huang Runzhu, ${ }^{1, *}$ and Song Tiehong ${ }^{2}$

${ }^{I}$ School of Civil and Architectural Engineering, Liaoning University of Technology, Jinzhou, Liaoning, 121001, P.R. China

${ }^{2}$ Key Laboratory of Songliao Aquatic Environment, Ministry of Education, Jilin Jianzhu University, Changchun, Jilin, 130118, P.R. China

\section{RETRACTION}

The Publisher and Editor have retracted this article [1] in accordance with good ethical practices. After a thorough investigations we believe that the peer review process was compromised. The article was published on-line on 31-07-2015.

\section{REFERENCE}

[1] G. Yanjiao, H. Runzhu, and S. Tiehong, "Using fenton oxidation method to advanced treatment of landfill leachate", Open. Chem. Eng. J., vol. 9, pp. 58-61, 2015.

(C) Yanjiao et al.; Licensee Bentham Open.

This is an open access article licensed under the terms of the Creative Commons Attribution-Non-Commercial 4.0 International Public License (CC BY-NC 4.0) (https://creativecommons.org/licenses/by-nc/4.0/legalcode), which permits unrestricted, non-commercial use, distribution and reproduction in any medium, provided the work is properly cited.

\footnotetext{
* Address correspondence to this author at the School of Civil and Architectural Engineering, Liaoning University of Technology, Jinzhou, Liaoning,
} 121001, P.R. China Tel: 13332189257; E- mail: gstiehong@163.com 